\title{
The effect of Plukenetia Volubilis residue on Omega-3 enriched eggs
}

\author{
Phakkharawat Sittiprapaporn \\ Assistant Professor and Head, Brain Science and Engineering Innovation Research Group, School of Anti-Aging and \\ Regenerative Medicine, Mae Fah Luang University, Bangkok, Thailand, and Department of Anti-Aging Science, School \\ of Anti-Aging and Regenerative Medicine, Mae Fah Luang University, Bangkok, Thailand
}

Background: Omega-3 DHA-enriched eggs provide the consumer with a value-added product that delivers a clear, functional benefit for an increasingly health conscious population. Human requires an omega-6: omega- 3 ratio of $4: 1$. The typical Thai diet which use a lot of vegetable oil for cooking provides a dramatically high 20:1 ratio. Lowering this ratio may reduce the risk of many chronic diseases including cardiovascular disease, coronary heart disease, Alzheimer's disease and some cancers. A healthy omega-6:omega- 3 ratio promotes the health benefits. The increased levels of DHA provides much needed nutrient essential to human brain functions e.g. brain activities. Aims and Objective: The purpose of this study was to study the Omega-3,6,9 concentration in raw and boiled eggs from hen feeding with Plukenetia Volubilis residue. Materials and Methods: A sample was selected from raw and boiled eggs feeding with Plukenetia Volubilis residue. Results: The result showed that total level of Omega-3 with $37869.65 \mathrm{mg} / 100 \mathrm{~mL}$ and Omega- 6 with $38490.67 \mathrm{mg} / 100 \mathrm{~mL}$ which was not much different in Plukenetia Volubilis oil. However total Omega-9 was only $8394.74 \mathrm{mg} / 100 \mathrm{~mL}$ compared to 37869.65 (Omega-3) and 38490.67 (Omega-6) which was almost 5 times lower than Omega-3,6.In addition, the comparison of Omega-3,6,9 concentration between raw and boiled eggs from hen feeding by Plukenetia Volubilis residue were also analyzed. The total level of Omega-3,6,9 in boiled eggs was higher than in raw eggs (Omega-3: $122.85 \mathrm{mg} / 100 \mathrm{~g}$ (raw egg), $158.12 \mathrm{mg} / 100 \mathrm{~g}$ (boiled eggs); Omega-6: $1479.18 \mathrm{mg} / 100 \mathrm{~g}$ (raw egg), $1766.53 \mathrm{mg} / 100 \mathrm{~g}$ (boiled eggs); Omega-9: $3009.16 \mathrm{mg} / 100 \mathrm{~g}$ (raw egg), $3375.23 \mathrm{mg} / 100 \mathrm{~g}$ (boiled eggs)), respectively. Conclusion: There is constantly growing demand from consumers for food products of superior health quality. We can increase the omega-3 content of eggs through the enrichment of the layers' diet with Plukenetia Volubilis. However, the relationship of Plukenetia Volubilis residue in chicken egg is still needed for further study.

Key words: Egg; Sacha Inchi; Plukenetia Volubilis residue

\section{INTRODUCTION}

Functional foods have become a popular topic in the food industry due to the push for healthier food products on supermarket shelves. There are many different types of fats in the foods we eat. Most Western diets contain too much saturated fat or saturated fatty acids (SFA). Many of us eat $20 \%$ more than the recommended maximum amount of SFA. The changing of omega-6/omega-3 polyunsaturated fatty acids (PUFA) in the food supply of Western societies occurred over the last 150 years

\section{Access this article online}

Website:

http://nepjol.info/index.php/AJMS DOI: 10.3126/ajms.v11i1.26525 E-ISSN: 2091-0576 P-ISSN: 2467-9100

Address for Correspondence:

Dr. Phakkharawat Sittiprapaporn, Assistant Professor and Head, Brain Science and Engineering Innovation Research Group, School of AntiAging and Regenerative Medicine, Mae Fah Luang University, Bangkok, Thailand. Tel No: +662 6644361. E-mail: wichian.sit@mfu.ac.th (c) Copyright AJMS 
plates of children, which leads to less than optimal levels of DHA intake..$^{5-9}$ Children are regularly consuming only $25 \%$ of the daily amount of DHA recommended by experts. The opportunity exists to fill this nutritional gap with naturally DHA-enriched foods that are without all of the additives and no "fishy" taste found in DHA-added products currently on the market. ${ }^{6-7,9-11} \mathrm{DHA}$ is a long chain fatty acid which is found in the tissues of salmon, mackerel and other fish. It is the only kind of omega-3 that is efficiently absorbed and taken directly into the cell membranes, and is an essential nutrient that helps support brain, eye and heart health. ${ }^{5,11}$ The human population can no longer rely on fish consumption as an adequate supply of DHA Omega-3 given that DHA and EPA have decreased in farmed fish due to the shift in raw materials used in aquaculture diets. ${ }^{5-6,10-11}$

The process to producing DHA-enriched foods is simple. When chickens are fed a DHA-enriched diet, the DHA is passed along to consumers via the eggs, providing additional nutrition to the consumer in each bite. ${ }^{9-11}$ DHAenriched functional eggs can be consumed in a tasty and convenient delivery system - the foods we already more enjoy eating compare with fish oil supplementation. Food products are now being fortified or enriched with DHA omega-3 in order to meet consumers' nutritional requirements. ${ }^{59-11}$ Omega-3 DHA-enriched eggs provide the consumer with a value-added product that delivers a clear, functional benefit for an increasingly health conscious population, while offering the retailer differentiation from competitors. The importance of DHA does not become any less significant with age. Thai foods use too much vegetable oil or omega- 6 for stir fried and deep-fried cooking. Levels of omega-3 fatty acids, such as DHA and eicosapentaenoic acid (EPA) have decreased in fish due to the shift in raw materials used in aquaculture diets. ${ }^{5,9-11}$ Adult consumers are not receiving an adequate amount of dietary DHA to balance the high ratio of omega- 6 to omega-3 fatty acids found in today's Thai diet. This disproportionate ratio may contribute to excess inflammation in the body, increasing the incidence of chronic disease. Plentiful levels of dietary DHA are shown to reduce the risk of coronary heart disease, depression, cancer, age-related mental decline and improve brain function. ${ }^{1-9,12-14}$

Human requires an omega-6:omega-3 ratio of 4:1. The typical Thai diet which use a lot of vegetable oil for cooking provides a dramatically high 20:1 ratio. Lowering this ratio may reduce the risk of many chronic diseases including cardiovascular disease, coronary heart disease, Alzheimer's disease and some cancers. In addition, a healthy omega6:omega-3 ratio promotes the health benefits. The increased levels of DHA provide much needed nutrient essential to human brain functions e.g. brain activities. ${ }^{5,7-13}$ The daily intake of omega-3 fatty acid should be in the range of $140 \mathrm{mg} /$ day to $667 \mathrm{mg} /$ day. ${ }^{15}$ However, a few countries reach the intake of only $250 \mathrm{mg}$ per day; therefore, the trend of enriched food products with omega- 3 fatty acids have emerged. Eggs are the potential source of n-3 fatty acids because they can be easily enriched with omega-3 PUFA through dietary modifications of the laying hens. ${ }^{16}$ Thus, the aim of this study was to study the Omega-3, 6, 9 concentration in raw and boiled eggs feeding with Plukenetia Volubilis residue.

\section{MATERIALS AND METHODS}

\section{Tools and equipments}

1. Sample: Plukenetia Volubilis oil was extracted by Sakda Sacha Inchi Inca (Thailand) Co., Ltd., Khongchai Sub-district, Khongchai District, Kalasin Province, Thailand.

2. Sample examination: The nutrient specification and fatty acid profile in Plukenetia Volubilis oil to prepare for developing DHA enriched eggs; raw and boiled eggs.

3. Research Protocol: This study was designed to compare the nutrient specification and fatty acid profile in Plukenetia Volubilis oil. Eggs were collected to test for nutrient specification and fatty acid profile at Central Laboratory (Thailand) Co., Ltd., KhonKhaen, Thailand.

\section{Materials}

Sample Type: Sacha Inchi Oil; Raw and Boiled Eggs Packaging: Glass Bottle Plastic Lid

Quantity: 1 bottle, Weight/Volume: $3000 \mathrm{~mL}$

Temperature: Room temperature, in good condition when received

\section{Reference methods}

1. Energy in-house method TE-CH-169 based on Compendium of Methods for Food Analysis Thailand, $1^{\text {st }}$ edition, 2003

2. Protein in-house method TE-CH-042 based on AOAC (2012), 981.10

3. Carbohydrate in-house method TE-CH-169 based on Compendium of Methods for Food Analysis Thailand, $1^{\text {st }}$ edition, 2003

4. Of which sugars in-house method TE-CH-169 based on Compendium of Methods for Food Analysis Thailand, $1^{\text {st }}$ edition, 2003

5. Fat IAOAC (2012), 922.06

6. Of which saturates in-house method TE-CH-208 based on AOAC (2012) 996.06

7. Fibre in-house method TE-CH-076 based on AOAC (2012) 985.29 
8. Sodium in-house method TE-CH-134 based on AOAC (2012) 984.27 by ICP-OES

9. Omega-3 in-house method TE-CH-208 based on AOAC (2012) 996.06

10. Omega-6 in-house method TE-CH-208 based on AOAC (2012) 996.06

11. Omega-9 in-house method TE-CH-208 based on AOAC (2012) 996.06.

\section{RESULTS}

In the present study, the Plukenetia Volubilis oil and eggs sample were sent to test for nutrient specification and fatty acid profile. A comparison nutrient profile for Plukenetia Volubilis Oil is presented in Tables 1-3.

\begin{tabular}{|c|c|c|}
\hline Typical value & Per serving (15 mL) & Per $100 \mathrm{~mL}$ \\
\hline Energy (kJ) & 519 & 3460 \\
\hline Energy (kCal) & 126 & 842 \\
\hline Protein $(g)(\% N \times 6.25)$ & 0.0 & 0.0 \\
\hline Carbohydrate $(\mathrm{g})$ of & 0.0 & 0.0 \\
\hline which sugars $(\mathrm{g})$ & 0.0 & 0.0 \\
\hline Fat $(\mathrm{g})$ of which & 14.0 & 93.5 \\
\hline saturates $(\mathrm{g})$ & 1.1 & 7.4 \\
\hline Fibre (g) & 0.0 & 0.0 \\
\hline Sodium (g) & 0.00 & 0.0 \\
\hline
\end{tabular}

Table 1 shows total level of energy as $3460 \mathrm{~kJ} / 100 \mathrm{~mL}$ and $842 \mathrm{kCal} / 100 \mathrm{~mL}$. However total fat is only $93.5 / 100 \mathrm{~mL}$ while of which saturates as $7.4 / 100 \mathrm{~mL}$, respectively.

\begin{tabular}{|c|c|c|}
\hline Typical value & Test Results (mg/100mL) & LOD \\
\hline Omega-3 & 37869.65 & - \\
\hline Omega-6 & 38490.67 & - \\
\hline Omega-9 & 8394.74 & - \\
\hline
\end{tabular}

Table 2 shows total level of Omega-3 with $37869.65 \mathrm{mg} / 100 \mathrm{~mL}$ and Omega-6 with $38490.67 \mathrm{mg} / 100 \mathrm{~mL}$ which is not much different. However total Omega-9 is only $8394.74 \mathrm{mg} / 100 \mathrm{~mL}$ compared to 37869.65 (Omega-3) and 38490.67 (Omega-6) which is almost 5 times lower than Omega-3,6.

Table 4 and Figure 1 show the comparison of Omega-3,6,9 concentrationbetween raw and boiled eggs from hen feeding by Plukenetia Volubilis residue. The total level of Omega-3,6,9 in boiled eggs is higher than in raw eggs (Omega-3: $122.85 \mathrm{mg} / 100 \mathrm{~g}$ (raw egg), $158.12 \mathrm{mg} / 100 \mathrm{~g}$ (boiled eggs); Omega-6: 1479.18 mg/100g (raw egg), $1766.53 \mathrm{mg} / 100 \mathrm{~g}$ (boiled eggs); Omega-9: $3009.16 \mathrm{mg} / 100 \mathrm{~g}$ (raw egg), $3375.23 \mathrm{mg} / 100 \mathrm{~g}$ (boiled eggs)), respectively.

\section{DISCUSSION}

DHA is an essential omega-3 fatty acid that human or animal cannot efficiently produce themselves; it must be taken through diet. Dietary sources of DHA such as salmon and mackerel are not commonly found on the plates of children and teenagers, which leads to less than optimal levels of DHA intake. ${ }^{17-18}$ Daily intake of omega-3 fatty acid should be in the range of $140 \mathrm{mg} /$ day to $667 \mathrm{mg} /$ day. However, a few countries reach the optimal intake of $250 \mathrm{mg}$ per day; therefore, the trend of enriched food products with omega-3 fatty acids have emerged. ${ }^{6-8,19-22}$ The omega 6:3 ratio is considered to be the factor that determines whether a diet is healthy or not. The ratio of $n-6 / n-3$ is critical in achieving an appropriate balance of highly unsaturated fatty acid derived function in the human body. This study produced the result showing a balance of the omega 6:3 ratio in Plukenetia Volubilis oil..$^{5-6,11,23-26}$

The omega 6:3 ratio is considered to be the factor that determines whether a diet is healthy or not. The ratio of $n-6 / n-3$ is critical in achieving an appropriate balance of highly unsaturated fatty acid derived function in the human body. ${ }^{9,27}$ Epidemiology and dietary intervention studies have concluded that while an exceptionally high omega 6:3 ratio promotes the development of many chronic diseases, a reduced omega-6:omega-3 ratio can prevent or reverse these diseases. ${ }^{9}$ The present study produced the result that adding Plukenetia Volubilis residue shows an increase in the omega 6:3 ratio in eggs (Table 4 and Figure 1).

Modification of yolk fatty acid through feeding of layers with different fat supplements has been reported previously. ${ }^{9}$ In the present study, supplementation of Plukenetia Volubilis residue resulted in increased DHA level in the egg yolk, and the concentration was found to have increased in boiled eggs compared to raw eggs (Figure 1). However, the overall performance of the layers, in terms of feed intake, egg production, egg weight, egg mass, albumin height, and haugh unit of the eggs, was not observed to have been greatly affected by feeding Plukenetia Volubilis residue. However, some previous studied revealed that feeding with fish oil could provide an enrichment of EPA and, especially, DHA in the egg yolk. Additionally, $3 \%$ of dietary menhaden oil could increase yolk DHA to $252 \mathrm{mg} /$ egg. $^{9.28-29}$ Adding 4\% fish oil to the hen diets for 8 weeks resulted in the increasing of the yolk DHA from $10.61 \pm 1.30 \mathrm{mg}$, of the control group, to $32.51 \pm 4.72 \mathrm{mg}$ per egg. ${ }^{9}$ In addition, in Kaewsutas, et al.'s study, It showed that eggs from the hens fed with $1 \%$ or $2 \%$ of microalgae were observed to have a higher DHA level per egg (1\% algae $=75.49 \pm 18.75 \mathrm{mg}, 2 \%$ algae $=114.35 \pm 16.66 \mathrm{mg})$, which was significantly different $(\mathrm{p}<0.05)$ from both the control group and the fish oil group. ${ }^{9}$ Eggs from hens 
Table 3: Fatty acid composition of raw eggs and boiled eggs from hen feeding by Plukenetia Volubilis residue

\begin{tabular}{|c|c|c|c|c|}
\hline \multirow[t]{2}{*}{ Fatty acid composition } & \multicolumn{2}{|c|}{ Raw eggs } & \multicolumn{2}{|c|}{ Boiled eggs } \\
\hline & $\mathrm{g} / 100 \mathrm{~g}$ & LOD & $\mathrm{g} / 100 \mathrm{~g}$ & LOD \\
\hline Saturated Fatty Acid & 2.64 & - & 3.17 & - \\
\hline Butyric acid $(C 4: 0)$ & - & 0.01 & - & 0.01 \\
\hline Caproic acid (C6:0) & - & 0.01 & - & 0.01 \\
\hline Caprylic acid (C8:0) & - & 0.01 & - & 0.01 \\
\hline Capric acid (C10:0) & - & 0.01 & - & 0.01 \\
\hline Undecanoic acid (C11:0) & - & 0.01 & - & 0.01 \\
\hline Lauric acid (C12:0) & - & 0.01 & - & 0.01 \\
\hline Triecanoic acid (13:0) & - & 0.01 & - & 0.01 \\
\hline Myristic acid (C14:0) & 0.03 & - & 0.03 & - \\
\hline Pentadecanoic acid (C15:0) & - & 0.01 & - & 0.01 \\
\hline Palmitic acid (C16:0) & 1.92 & - & 2.26 & - \\
\hline Heptadecanoic acid (17:0) & 0.02 & - & 0.02 & - \\
\hline Stearic acid (C18:0) & 0.67 & - & 0.86 & - \\
\hline Arachidic acid (C20:0) & - & 0.01 & - & 0.01 \\
\hline Heneicosanoic acid (C21:0) & - & 0.01 & - & 0.01 \\
\hline Behenic acid (C22:0) & - & 0.01 & - & 0.01 \\
\hline Tricosanoic acid (C23:0) & - & 0.01 & - & 0.01 \\
\hline Lignoceric acid (C24:0) & - & 0.01 & - & 0.01 \\
\hline Unsaturated Fat & 4.82 & - & 5.55 & - \\
\hline Myristoleic acid (C14:1) & - & 0.01 & - & 0.01 \\
\hline Pentadecenoic acid (C15:1) & - & 0.01 & - & 0.01 \\
\hline Palmitoleic acid (C16:1) & 0.21 & - & 0.23 & - \\
\hline Heptadecenoic acid (C17:1) & - & 0.01 & - & 0.01 \\
\hline Oleic acid (C18:1, Omega-9) & 2.98 & - & 3.35 & - \\
\hline Eicosenoic acid (C20:1, Omega-9) & 0.02 & & 0.03 & \\
\hline Linoleic acid (C18:2, Omega-6) & 1.24 & - & 1.44 & - \\
\hline Erucic acid (C22:1, Omega-9) & - & 0.01 & - & 0.01 \\
\hline Nervonic acid (C24:1, Omega-9) & - & 0.01 & - & 0.01 \\
\hline Linoleic acid (C18:2, Omega-6) & 1.24 & - & 1.44 & - \\
\hline g-Linolenic acid (C18:3, Omega-6) & - & 0.01 & 0.01 & \\
\hline Linoleic acid (C18:3, ALA, Omega-3) & 0.04 & - & 0.05 & - \\
\hline Eicosadienoic acid (C20:2, Omega-6) & 0.02 & - & 0.02 & - \\
\hline cis-8,11,14-Eicosatrienoic acid (C20:3, Omega-6) & 0.02 & - & 0.02 & - \\
\hline Eicosatrienoic acid (C20:3, Omega-3) & - & 0.01 & - & 0.01 \\
\hline Arachidonic acid (C20:4, ARA, Omega-6) & 0.20 & - & 0.28 & - \\
\hline Docosadienoic acid (C22:2, Omega-6) & - & 0.01 & - & 0.01 \\
\hline Eicosapentaenoic acid (C20:5, Omega-3) & - & 0.01 & - & 0.01 \\
\hline Docosahexaenoic acid (C22:6, DHA, Omega-3) & 0.08 & - & 0.11 & - \\
\hline Elaidic acid (C18:1 trans) & 0.01 & - & 0.01 & - \\
\hline Linolelaidic acid (C18:2, trans) & - & 0.01 & - & 0.01 \\
\hline Monounsaturated fatty acid & 3.22 & - & 3.62 & - \\
\hline Polyunsaturated fatty acid & 1.60 & - & 1.93 & - \\
\hline Trans Fat & - & 0.01 & - & 0.01 \\
\hline
\end{tabular}

Table 4: Omega-3,6,9 concentration compared between raw and boiled eggs from hen feeding by Plukenetia Volubilis residue

\begin{tabular}{lccc}
\hline Typical value & Raw eggs & & Boiled eggs \\
\cline { 2 - 2 } & $\begin{array}{c}\text { Test results } \\
(\mathbf{m g} / \mathbf{1 0 0} \mathbf{g})\end{array}$ & & $\begin{array}{c}\text { Test results } \\
(\mathbf{m g} / \mathbf{1 0 0 g})\end{array}$ \\
\hline Omega-3 & 122.85 & 158.12 \\
Omega-6 & 1479.18 & 1766.53 \\
Omega-9 & 3009.16 & 3375.23 \\
\hline
\end{tabular}

fed with $4 \%$ fish oil in the diet were found to have a DHA level of $232.50 \pm 31.19 \mathrm{mg} / 100$ gram of egg yolk or $57.45 \pm 8.24 \mathrm{mg} / 100$ gram of whole egg, which gives the result as $32.51 \pm 4.72 \mathrm{mg} / \mathrm{egg} .{ }^{9}$ The incorporation of yolk n-3 fatty acid by up to $200 \mathrm{mg}$ /yolk is significant as this amount of $n-3$ FA is comparable with that found in a $100 \mathrm{~g}$ serving of lean cold-water fish. ${ }^{29}$ In general, the fatty acid profile of the egg is dependent on the type of diet the hens are fed. The level of essential fatty acids in the egg yolk achieved by the inclusion of different sources of fatty acids in the diet varies considerably. ${ }^{29}$

There is constantly growing demand from consumers for food products of superior health quality. As the approved ratio is actually between $4: 1$ and $10: 1,{ }^{30}$ supplementation of omega-3 fatty acid in the diet promotes a qualitative change in the fatty acid profile in the egg yolk and reduces the $n-6 / n-3$ ratio to a more beneficial level with regard to 


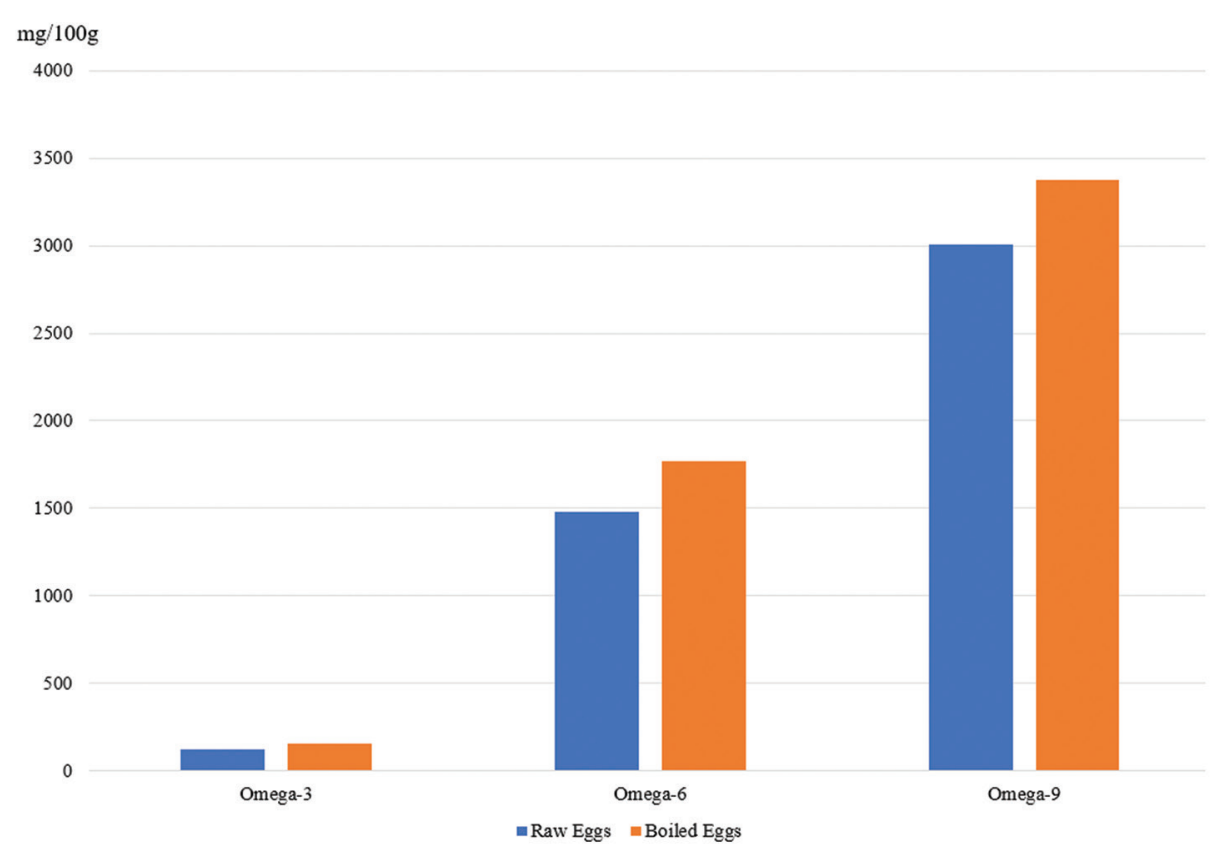

Figure 1: Omega-3,6,9 concentration compared between raw and boiled eggs from hen feeding by Plukenetia Volubilis residue

human nutritional needs. ${ }^{9,31}$ The present study can increase the omega-3 content of eggs through the enrichment of the layers' diet with Plukenetia Volubilis residue. This supplement can equal the omega 6:3 ratio in the egg yolk to the optimal ratio. The fatty acid composition of an ingredient has a direct effect on fat utilization or deposition in poultry. ${ }^{32}$ Longer chain fatty acids including omega-3 fatty acids EPA and DHA are almost exclusively deposited for storage in the form of phospholipids, particularly phosphatidylethanolamine in egg yolk. ${ }^{33}$ Taking advantage of dietary omega-3 fatty acid deposition into yolk, producers are able to create value-added ALA, EPA, and DHA enriched eggs. ${ }^{47,11-14,17,33-34}$

According to the European Union Guidelines (2010), the developing DHA-enriched egg has to be at least $180 \mathrm{mg} / 100$-gram whole egg. ${ }^{9}$ The panel of the European Union Food Safety Authority (2010) considers that the intake of EPA and DHA of about $250 \mathrm{mg} /$ day is required to obtain the claimed effect as regards eye, brain, and heart health. Considering that most egg consumers eat two eggs as a serving, the equivalent of $>228 \mathrm{mg}$ DHA could be obtained from a typical serving of these eggs. 'Therefore, the consumption of microalgae DHA-enriched egg could be beneficial to the eye, brain, and heart of the consumers.' Feeding Plukenetia Volubilis residue might promote DHA deposition in the egg. The panel of European Union Food Safety Authority (2010) considers that the intake of EPA and DHA of about $250 \mathrm{mg} /$ day is required to obtain the claimed effect as regards eyes, brain, and heart health. Supplementation with Plukenetia Volubilis residue might equal the DHA concentration to egg. Therefore, the consumption of Plukenetia Volubilis residue from DHAenriched egg could be beneficial to eyes, brain, and heart of the consumers. ${ }^{1,5-8,11,32,35-36}$

\section{CONCLUSION}

Modification of the fatty acid profile in Plukenetia Volubilis residue to equal concentration of DHA omega-3 fatty acids of the omega 6:3 ratio has the potential for improving brain health of consumers. The results of this study revealed that manipulation of Omega-3 fatty acids to optimal level could be possible by supplementing specific methods.

\section{ACKNOWLEDGEMENT}

This research was supported by research funding from Mae Fah Luang University grant (MFU-grant no. 61210120006), Mae Fah Luang University grant (Electroencephalogram Laboratory 2019), and Brain Science and Engineering Innovation Research Group, Mae Fah Luang University grant 2019 (MFU-grant no. 611U109005), and 2020 Thailand.

\section{REFERENCES}

1. Burns-Whitmore B, Haddad E, Sabaté J and Rajaram S. Effects of supplementing n-3 fatty acid enriched eggs and walnuts on cardiovascular disease risk markers in healthy free-living lacto-ovo-vegetarians: a randomized, crossover, free-living intervention study. Nutrition Journal 2014; 13: 29.

2. Carver JD, Benford VJ, Han B and Cantor AB. The relationship between age and the fatty acid composition of cerebral cortex 
and erythrocytes in human subjects. Brain Research Bulletin 2011; 56: 79-85.

3. European Food Safety Authority. Scientific opinion on the tolerate upper intake level of eicosapentanoeic acid (EPA), docosahexaenoic acid (DHA) and docosapentaenoic acid (DPA). European Food Safety Authority Journal 2012; 10(7): 2815.

4. Freund-Levi $\mathrm{Y}$, Eriksdotter-Jonhagen $\mathrm{M}$, Cederholm $\mathrm{T}$ and Basun H. Omega-3 fatty acid treatment in 174 patients with mild to moderate Alzheimer disease: OmegAD study: a randomized double-blind trial. Arch Neurol 2006; 63: 1402-1408.

5. Kaewsutas M, Sarikaphuti A, Nararatwanchai T, Sittiprapaporn $P$ and Patchanee P. Electroencephalographic study of microalgae DHA omega-3 egg consumption on cognitive function. J Funct Foods 2017; 29: 46-52.

6. Barberger-Gateau P, Raffaitin C, Letenneur L, Berr C, Tzourio $\mathrm{C}$ and Dartigues JF. Dietary patterns and risk of dementia: the three-city cohort study. Neurology 2007; 69(20): 1921-1930.

7. Barclay WR, Meager KM and Abril JR. Heterotrophic production of long chain omega-3 fatty acids utilizing algae and algar-like microorganisms. Journal of Apply Phycology 1994; 6: 123-129.

8. Boucher O, Burden MJ, Muckle G, Saint-Amour D, Ayotte P and Dewailly P. Neurophysiologic and neurobehavioral evidence of beneficial effects of prenatal omega- 3 fatty acid intake on memory function at school age. American Journal of Clinical Nutrition 2011; 93: 1025-1037.

9. Kaewsutas M, Sarikaphuti A, Nararatwanchai T, Sittiprapaporn $P$ and Patchanee P. The effects of dietary microalgae (Schizochytrium spp.) and fish oil in layers on docosahexaenoic acid omega-3 enrichment of the eggs. J Appl Animal Nutrition 2016; 4: e7.

10. Arterburn LM, Hall EB and Oken H. Distribution, interconversion, and dose response of n-3 fatty acids in humans. Am J Clin Nutr 2006; 83(suppl): 1467S-176S.

11. Richardson AJ, Burton JR, Sewell RP, Spreckelsen TF and Montgomery P. Docosahexaenoic acid for reading, cognition and behavior in children aged 7-9 years: A randomized controlled trial (The DOLAB study). Plus one 2010; 7(9): e43909.

12. Fontani G, Corradeschi F, Felici A, Migliorini S and Lodi L. Cognitive and physiological effects of Omega-3 polyunsaturated fatty acid supplementation in healthy subjects. European Journal of Clinical Investigation 2005; 35: 691-699.

13. Gustafson KM, Colombo J and Carlson SE. Docosahexaenoic acid and cognitive function: Is the link mediated by the autonomic nervous system? Prostaglandins, Leukotrienes and Essential Fatty Acids 2008; 79: 135-140.

14. Innis SM. Dietary (n-3) Fatty acids and brain development. Journal of Nutrition2007; 137: 855-859.

15. Lemahieu C, Bruneel C, Termote-Verhalle R, Muylaert K, Buyse $\mathrm{J}$ and Foubert I. Impact of feed supplementation with different omega-3 rich microalgae species on enrichment of eggs of laying hens. Food Chemistry 2013; 141: 4051-4059.

16. Ahmad S, Ahsan-ul-Haq YM and Nawaz $\mathrm{H}$. Effect of feeding canola oil and vitamin A on the fatty acid profile of egg yolks in laying hens. Pakistan Journal of Nutrition 2010; 9(2): 191-194.

17. International society for the study of fatty acids and lipids, "PUFA recommendation,” [Online] 2015 [Cited 2014 November 28] Available from http://www.issfal.org.

18. Kuratko CN, Barrett EC, Nelson EB and Salem N. The relationship of Docosahexaenoic acid (DHA) with learning and Behavior in healthy children: A Review. Nutrients 2013; 5: 2777-2810.

19. Labrousse VF, Nadjar A, Joffre $C$ and Costes L. Short-term long chain omega3 diet protects from neuroinflammatory process and memory impairment in aged mice. Plos One 2012; 7(5): e36861.

20. Logan AC. Omega-3 fatty acids and major depression: A primer for the mental health professional. Lipids in Health and Disease 2004; 3: 25.

21. Makrides M, Gibson RA, Mcphee AJ, Collins CT, Davis PG and Doyle LW. Neurodevelopmental outcomes of preterm infants fed high dose docosahexaenoic acid.Journal American Medical Association 2009; 301: 175-182.

22. McNamara RK and Carlson SE. Role of omega-3 fatty acids in brain development and function: Potential implications for the pathogenesis and prevention of psychopathology. Prostaglandins, Leukotrienes and Essential Fatty Acids 2006; 75: 329-349.

23. McNamara RK. Deciphering the role of docosahexaenoic acid in brain maturation and pathology with magnetic resonance imaging. Prostaglandins, Leukotrienes and Essential Fatty Acids 2013; 88: 33-42.

24. McNamara RK, Able J, Jandacek R, Rider T, Tso $P$ and Eliassen JC. Docosahexaenoic acid supplementation increases prefrontal cortex activation during sustained attention in healthy boys: A placebo-controlled, dose-ranging, functional magnetic resonance imaging study. Am J Clin Nutr 2010; 91: 1060-1067.

25. Muldoon MF, Ryan CM, Sheu L, Yao JK, Conklin SM and Manuck SB. Serum Phospholipid Docosahexaenoic acid is associated with cognitive functioning during middle adulthood. The Journal of Nutrition, Ingestive Behavior and Neurosciences 2010; 11: 848-853.

26. Muskiet FA, van Goor SA, Kuipers RS and Velzing-Aarts FV. Long-chain polyunsaturated fatty acids in maternal and infant nutrition. Prostaglandins. Leukotrienes and Essential Fatty acids 2006; 75: 135-144.

27. Yannakopoulos AL, Tserveni-Gousi AS, Yannakakis $S$ and Yamoustaris A. Yolk fatty acid composition of $n-3$ eggs during the laying period. $\mathrm{Xl}^{\text {th }}$ European Symposium on the Quality of Eggs and Egg Products, The Netherlands 2005.

28. Van Elswky ME, Dawson PL and Sams AR. Dietary menhaden oil influences sensory characteristics and headspace volatiles of shell eggs. Journal of Food Sciences. 1995; 60: 85-89.

29. Van Elswky ME. Comparison of $n-3$ fatty acid sources in laying hen rations for improvement of whole egg nutritional quality: a review. British Journal of Nutrition 1997; Suppl. 1: S61-S69.

30. Mazalli MR, Faria DE, Salvador D and Ito DT. A comparison of the feeding value of different sources of fats for laying hens: 2 . Lipid, cholesterol and vitamin E profiles of egg yolk. Journal of Applied Poultry Research 2004; 13:280-290.

31. Simoupoulos AP. The importance of the ratio of omega-6/ omega-3 essential fatty acids. Biomed Pharmacother 2002; 56(8): 365-79.

32. Haug A, Nyquist NF, Thomassen M, Hostmark AT and Ostbye TK. $\mathrm{N}-3$ fatty acid intake altered fat content and fatty acid distribution in chicken breast muscle, but did not influence mRNA expression of lipid-related enzymes. Lipid Heal Dis 2014; 13: 92.

33. Her IJ, Persia ME and Bobeck EA. Comparative omega-3 fatty acid enrichment of egg yolks from first-cycle laying hens fed flaxseed oil or ground flaxseed. Poultry Science 2017; 96: 17911799.

34. Lemahieu C, Bruneel C, Termote-Verhalle R, Muylaert K, Buyse $\mathrm{J}$ and Foubert I. Impact of feed supplementation with different omega-3 rich microalgae species on enrichment of eggs of laying hens. Food Chemistry 2013; 141: 4051-4059.

35. Herber SM and Van Elswyk ME. Dietary marine algae promote efficient deposition of $n-3$ fatty acids for the production of enriched shell eggs. Poultry Science 1996; 75: 1501-1507.

36. Cherian $G$ and Sim JS. Effect of feeding full fat flax and canola seeds to laying hens on the fatty-acid composition of eggs, embryos, and newly hatched chicks. Poult Sci 1991; 70: $917-922$ 
Authors Contribution:

PS- Concept and design of the study, statistically analyzed and interpreted, manuscript preparation, critical revision of the manuscript.

Work attributed to:

Brain Science and Engineering Innovation Research Group

School of Anti-Aging and Regenerative Medicine, Mae Fah Luang University, Thailand

Orcid ID:

Dr. Phakkharawat Sittiprapaporn - (1) https://orcid.org/0000-0002-4103-9396

Source of Support: Mae Fah Luang University grant (MFU-grant no. 61210120006); Mae Fah Luang University grant (Electroencephalogram Laboratory

2019); Brain Science and Engineering Innovation Research Group, Mae Fah Luang University grant 2019 (MFU-grant no. 611U109005), and 2020

Thailand, Conflict of Interest: None. 